\title{
Staged cost optimization of urban storm drainage systems based on hydraulic performance in a changing environment
}

\author{
M. Maharjan, A. Pathirana, B. Gersonius, and K. Vairavamoorthy \\ UNESCO-IHE Institute for Water Education, P.O. Box 3015, 2601 DA Delft, The Netherlands
}

Received: 17 April 2008 - Published in Hydrol. Earth Syst. Sci. Discuss.: 17 June 2008

Revised: 31 March 2009 - Accepted: 1 April 2009 - Published: 9 April 2009

\begin{abstract}
Urban flooding causes large economic losses, property damage and loss of lives. The impact of environmental changes, mainly urbanization and climatic change, leads to increased runoff and peak flows which the drainage system must be able to cope with to reduce potential damage and inconvenience. Allowing for detention storage to compliment the conveyance capacity of the drainage system network is one of the approaches to reduce urban floods. Contemporary practice is to design systems against stationary environmental forcings - including design rainfall, landuse, etc. Due to the rapid change in the climate- and the urban environment, this approach is no longer appropriate, and explicit consideration of gradual changes during the life-time of the drainage system is warranted. In this paper, a staged cost optimization tool based on the hydraulic performance of the drainage system is presented. A one dimensional hydraulic model is used for hydraulic evaluation of the network together with a genetic algorithm based optimization tool to determine optimal intervention timings and responses over the analysis period. The model was applied in a case study area in the city of Porto Alegre, Brazil. It was concluded that considerable financial savings and/or additional level of flood-safety can be achieved by approaching the design problem as a staged plan rather than one-off scheme.
\end{abstract}

\section{Introduction}

Floods are a recurrent threat to life and property. An increasing trend in extreme flood events can be observed in many countries around the world. Annual statistics of natural disasters over the past 30 years show that the number of floods is rapidly increasing around the world in comparison

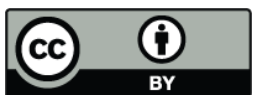

Correspondence to: A. Pathirana (a.pathirana@unesco-ihe.org) with all other disasters (Dutta et al., 2003). In 2007, more than 16 thousand people were killed, over 234 million others were affected and almost 75 billion US\$ worth of assets were damaged, of which floods and windstorms remain the most important source. They accounted for more than $86 \%$ of the overall disaster mortality and hydro-meteorological disasters accounted for more than $98 \%$ of total affected (Sapir, 2008).

With urbanization, the impermeable surfaces increase whereas the natural water courses are changed into drainage systems. As a result, runoff increases which yields more frequent and severe floods. This leads to the requirement of proper drainage solutions to reduce flooding and the possible occurrence of inconvenience, damage and adverse health impacts.

With global climate change, more extreme climate events have been predicted in different regions and as consequences of such extreme events, large floods are predicted (Houghton et al., 2001). In addition to that, increased imperviousness due to changes in land cover and use has increased the exposure and vulnerability to flash floods (Gruntfest and Ripps, 2000). Scientists and engineers have been constantly experimenting with various means to reduce this vulnerability and exposure of urban areas by various structural and nonstructural measures. Apart from the traditional approaches that primarily involve improvements in conveyance capacity, on-site measures, such as provision of detention ponds, infiltration ponds, rain water collection and reuse etc., can be used to reduce the runoff peaks and reduce downstream flooding by providing flood attenuation during rainfall events (Woods-Ballard et al., 2007). Further, they are often part of integrated urban water management solutions that provide other positive outcomes besides flood control.

The term "Whole Life Costing" (WLC) has been around for two decades stemming from the recognition that initial capital costs often represent only a small portion of the lifetime costs of an infrastructure system. Whole life costing approaches have been shown to provide an ideal platform for

Published by Copernicus Publications on behalf of the European Geosciences Union. 
the evaluation of the sewer system by taking account of system behaviour, performance and regulation within a sensible economic and engineering framework (Shepherd et al., 2004). The term "whole life costing" includes all the cost components of the asset from planning, designing, construction, operation, maintenance, repair, rehabilitation, to salvage value, evaluated in terms of net present value. However, the use of the term "whole life cost" in this study covers only flood cost and intervention cost.

This paper presents a whole life (staged) cost optimization tool that can be used to determine the planning of detention delivery based on the aspirational hydraulic performance of the storm water drainage system for flood control and it provides a basis for proactive decision making in a changing environment.

We implement a hydraulic analysis based genetic algorithm optimizer as an aid to determine staged intervention strategies for urban storm water systems subjected to gradualy changing external forcings like climate change, demographic and land use changes, etc. Applying the tool to an urban system in Brazil, we argue that staged approaches are not only more flexible as they allow the decision makers to keep options open against the backdrop of a large degree of uncertainty, but also show that they are economically efficient without sacrificing the degree of safety provided. The following section explains the model implementation, followed by data used for the model together with major assumptions made. Then we present the case study application in Porto Alegre, Brazil, and show that due to the significant flexibility offered by staged-design at no additional cost, it is indeed a better design paradigm compared to traditional "implement once and operate" schemes. There is a significant degree of possible variability in input variables used in this study, due to the large uncertainty involved in future scenarios. In order to ensure that the qualitative conclusions drawn are not affected by this, we conducted an analysis of the sensitivity of each input variable to the model prediction. Selected sensitivity results are presented. Finally there is a discussion on the results obtained, together with general conclusions.

\section{Whole life cost optimization model}

The decision making tool developed consists of a dynamic hydraulic model coupled with a lumped physically-based hydrological model, that computes runoff from urban catchments and flow in conveyance elements. Flooding is considered only in volumetric terms (as overflow from sewers), not considering the inundation effects explicitly. We use EPA Storm Water Management Model (SWMM) version 5.0 (EPA, 2008) as the hydrologic/hydraulic simulator in the tool. SWMM is a dynamic rainfall-runoff simulation model used for single event or long-term (continuous) simulation of runoff quantity and quality from primarily urban areas. It is a physically based discrete-time simulation model which em- ploys the principles of conservation of mass, energy and momentum wherever appropriate. It solves the numerical equations explicitly and has the ability to automatically adjust the time step as needed to maintain the numerical stability (Rossman, 2004). Apart from these important features, SWMM is also available in free open source form which makes it convenient to be adopted for the present purpose.

Hydrological routing was implemented as a lumped physically-based model based on single hillslope analogy, using the SCS curve number runoff computation (Gupta, 2001). The curve number method was adopted because the available data for Porto Alegre uses this approach. The hydraulic network model was developed using the full one dimensional Saint Venants equation. The hydraulic performance of the network model was analysed to find out the specific locations where flooding occurs for the $1 \mathrm{~h} 50$ years design storm. An initial analysis of the drainage network showed that the response times of various sub-catchments, observed at different nodes of the network, vary from $15 \mathrm{~min}$ to $45 \mathrm{~min}$. This justified the selection of $1 \mathrm{~h}$ design storm. While there is no quantitative data on flooding history, the qualitative input from the authorities in Porto Alegre was used to validate these. Public open spaces were selected to provide detention ponds.

We assumed that the detention storage is provided in a staged fashion, where interventions are implemented at regular time periods (10 years in the example). For example, it is possible for a location to have no detention storage until the 20th year, then $2000 \mathrm{~m}^{3}$ storage can be build at that stage and a further $5000 \mathrm{~m}^{3}$ storage at the end of 40th year. The advantage of this scheme is the possibility to defer investment until the most opportune moment (due to increasing tendencies in environmental forcings like rainfall, landuse change etc.). The detention schedule is optimized using a total cost function that consists of the cost of interventions and residual flood damages, as objective function.

The flood damage is computed in terms of expected annual damage, which can be defined as:

$E(D)=\int_{f=0}^{\infty} D(z) d f$

Where $E(D)$ is the expected annual damage, $D(z)$ is the flood damage caused by flood depth $z, f$ is the frequency of occurrence (inverse of return period) and $z$ is a function of flood depth and extent. In this study we use a major assumption that the flood volume is linearly related to the damage $D(z)$, which is not strictly valid for complex urban terrain. Further instead of the continuous integral, a difference approximation that involves a set of return periods was used (1 year, 5 year, 20 year and 50 year). Equation (2) shows this computation. Equation (3) shows the computation of the net 


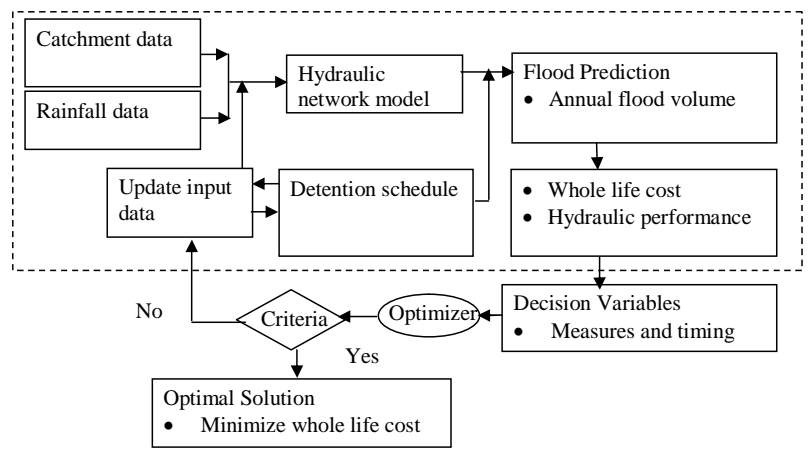

Fig. 1. Conceptual diagram of whole life cost optimization model.

present value of total intervention costs (in this case construction of detention storage facilities at different stages).

$\mathrm{TPFC}=\sum_{j=1}^{n \text { steps }}\left[\left\{\sum_{i=1}^{n \text { return } p}\left(\frac{V_{i+1}+V_{i}}{2} \times C_{f} \times\left(\frac{1}{R_{i}}-\frac{1}{R_{i+1}}\right)\right)\right\}_{j} \times F D_{f j}\right]$ (2)

$\mathrm{TPIC}=\sum_{j=1}^{n \text { steps }}\left[\left\{\sum_{i=1}^{n \text { interv }}\left(S A_{i} \times S D_{\max (i)} \times C_{d}\right)\right\}_{j} \times I D_{f j}\right]$

Where, TPFC is the total present flood cost, $R_{i}$ is the $i$-th return period, $V_{i}$ is the volume flooded due to $i$-th return period, $C_{f}$ is the unit cost of flooding per unit volume, TPIC is the total present intervention cost, $n$ steps is the number of time steps, $n$ interv is the number of intervention locations, $S A_{i}$ is the storage area at the intervention location, $S D_{\max }$ is the storage depth, $C_{d}$ is the unit cost of detention per unit volume, $F D_{f}$ is the flood discount factor and $I D_{f}$ is the intervention discount factor for each time step $j$ calculated using the Eqs. (4) and (5) respectively.

$$
\begin{aligned}
& F D_{f j}=\sum_{i=0}^{\Delta t-1} \frac{1}{\left(1+\frac{r}{100}\right)^{\mathrm{tstep} * \Delta t+i}} \\
& I D_{f j}=\frac{1}{\left(1+\frac{r}{100}\right)^{\mathrm{tstep} * \Delta t+\frac{\Delta t}{2}}}
\end{aligned}
$$

Where, $\Delta t$ is time duration of each time step and $r$ is discount rate in percentage; $j$ is the corresponding time step (tstep).

The optimized cost among the number of generations is thus given by Eq. (6).

Optimized cost $=\min (\mathrm{TPFC}+\mathrm{TPIC})$

There are numerous approaches to implement the optimization scheme for this problem. We selected genetic algorithms (Fraser, 1957; Goldberg, 1989), largely due to their robustness in handling complex problems that display large variability and intermittency in input parameters and a large degree of nonlinearity in functional relationships (Mitchell, 1997). Genetic algorithms are implemented as a computer

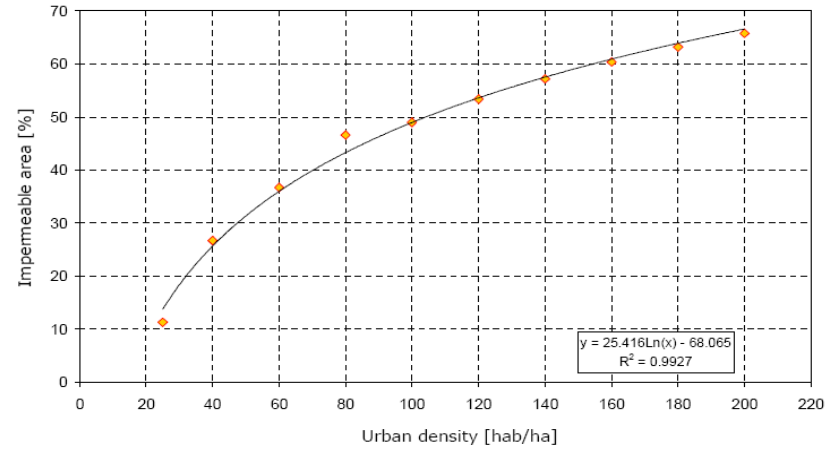

Fig. 2. Relations of urban density with impervious percentage.

simulation in which a population of abstract representations called chromosomes are implemented as vectors of bits ( 0 or 1), integers or real numbers. We used real-number based chromosomes in this study. Initially many individual solutions are randomly generated to form an initial population. Then the process of "evolution" is mimicked by a large number of generation steps. During each successive generation, a proportion of the existing population is selected as "parents" to breed a new generation. Individual solutions are selected through a fitness-based process, where fitter solutions are typically more likely to be selected. Due to this "selection pressure", statistically the population evolves in a direction that increases the fitness of its members. Compared to calculus based optimization schemes that are used in simpler problems, one drawback of genetic algorithms is the inability to guarantee that a reached solution represents the true global optimum of the domain, because it can be trapped in local optima or even temporarily stranded in a mild gradient sector. It is possible to overcome this dilemma at least to some degree by extensive repetition of trials with random initializations. This is quite practical with fast computers available today, particularly with the ease with which the genetic algorithms render themselves to distributed parallel computing.

The development of the numerical optimization scheme is done using a genetic algorithm optimizer with whole life cost minimization as objective function. The integration of the whole life cost component is carried out with numerical optimization and a hydraulic simulator (SWMM) with interfacing code written in the $C$ language.

Figure 1 gives the conceptual diagram of the model.

\section{Data used for the cost optimization model}

A variety of data types are needed as input for the optimization model. Most of these are, in the present study, based on major simplifications. Several simplifications are a direct consequence of the uncertainty and unpredictability of future change pressures, both local and global. 


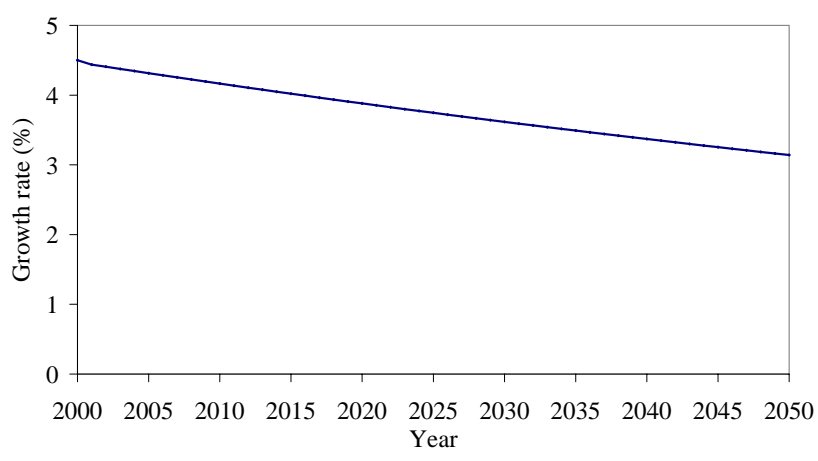

Fig. 3. Forecasted population growth rate for Porto Alegre, Brazil.

\subsection{Land-use and climate change related data}

Climate change and urbanization, the two basic phenomena of the changing environment are parameterized to take account of their effects on urban drainage. The change in precipitation with time is estimated based on predictions from climate studies. The current rainfall time series are multiplied by a rainfall increase rate of the corresponding time step to get the time series data for that time step.

An indirect method of evaluating the impact of urbanization on drainage is used, relating the population density with the extent of impermeable cover, which in turn is directly correlated with runoff coefficients. Figure 2 gives a typical relationship of the impermeable area with urban density (Campana and Tucci, 1994). For population densities below $20 \mathrm{hab} / \mathrm{ha}$ (beyond the curve in Fig. 2), a linear relation is used as shown in Eq. (7).

For density, $D<20$ hab/ha, impf $=0.403 * D$

Where, Impf is the impervious area (\%) and $U D$ is the urban population density.

The estimation of the impervious fraction thus depends on the population density; ultimately the population density is estimated at different times using a population growth rate for the area as represented in Fig. 3, which is calculated from the available population data of Porto Alegre. (Source: Planet Barsa Ltda.).

\subsection{Rainfall data}

The rainfall data for this study is derived from an IDF relationship given by Eq. (8) (Bemfica, 1999). Time series data are derived from the cumulative rainfal using the alternating block method (Chow et al., 1988) (Fig. 4). Four return periods, 1 year, 5 years, 20 years and 50 years, are considered for the study.

$i=\frac{826.8 * R^{0.143}}{(t+13.3)^{0.79}}$

Where, $i$ is the intensity in $\mathrm{mm} / \mathrm{hr}, R$ is return period in years, $t$ is the duration of rainfall.

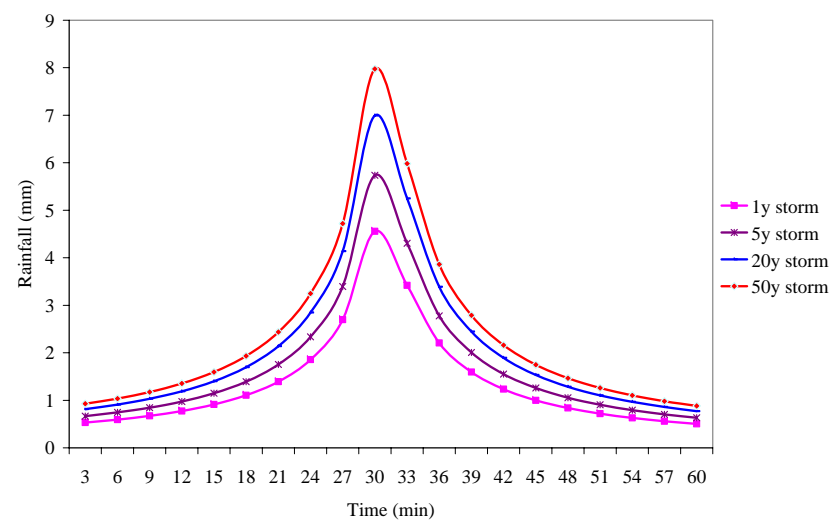

Fig. 4. Design rainfall time series data for different return periods. The computations are based on Eq. (8) and converted to rainfall depths (mm).

\subsection{Soil data and estimation of corresponding model pa- rameter}

For the computation of runoff in SWMM, the SCS curve number method is used. The mathematical relationship between the impervious factor and curve number is used to estimate the curve number of different hydrological soil groups. The approximate relationships between $\mathrm{CN}$ and impervious fraction for different hydrological soil groups are given in Eqs. (9) to (13).

For $\mathrm{A}, \mathrm{CN}=0.58 \mathrm{Impf}+39.301$

For $\mathrm{B}, \mathrm{CN}=0.3776 \mathrm{Impf}+60.542$

For $\mathrm{C}, \mathrm{CN}=0.2448 \mathrm{Impf}+73.916$

For D, $\mathrm{CN}=0.188 \mathrm{Impf}+80.205$

\subsection{Genetic algorithm parameters}

The genetic algorithm procedure starts with the initialization of a random population that corresponds to a series of trial detention schedules, followed by selection based on fitness function and breeding. The process undergoes a number of repetitions to find the "best solution" meeting the objective function. The numerical implementation of the genetic algorithm requires the following parameters to be defined: the population size, the stopping criteria, the length of the chromosome (should correspond to the number of values in the detention schedule), the crossover probability and the mutation probability. For this study, a population size of 10, a no of variables of 20 , a cross over probability of 0.8 , a mutation probability of 0.5 , a tournament size of 5 , and a range of real mutation of 0.01 are used. The steady state generation condition is adopted by defining the number of steady generations without any improvements to 10 numbers of constant values, instead of defining the maximum generation size, in order to allow the GA to search for the best optimal values. 


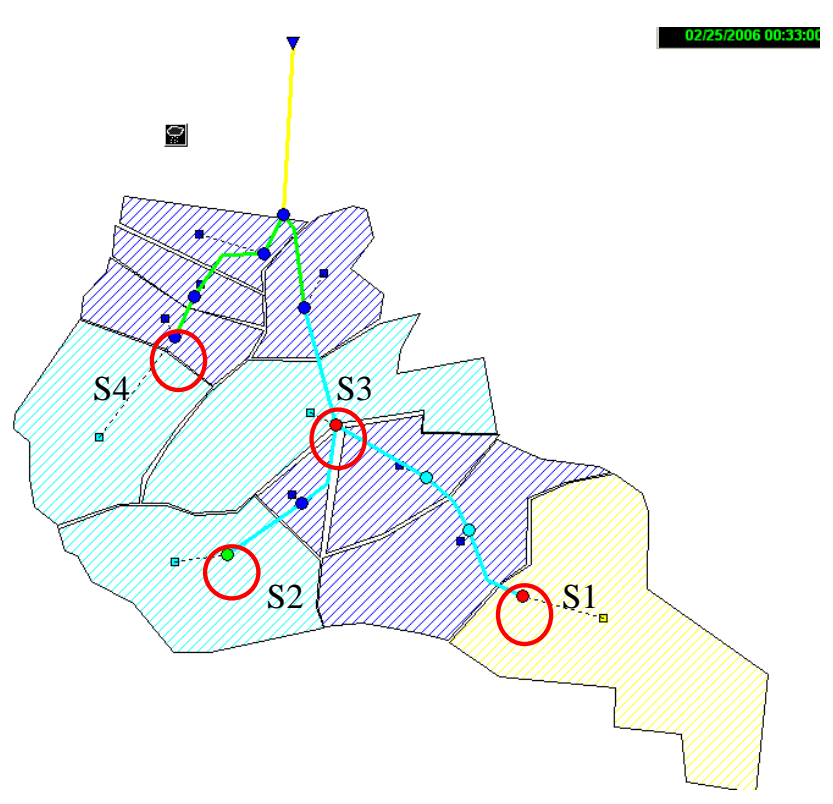

Fig. 5. Existing drainage network with flooded nodes (dark blue). The Four potential locations for implementing detention storage are shown with red circles.

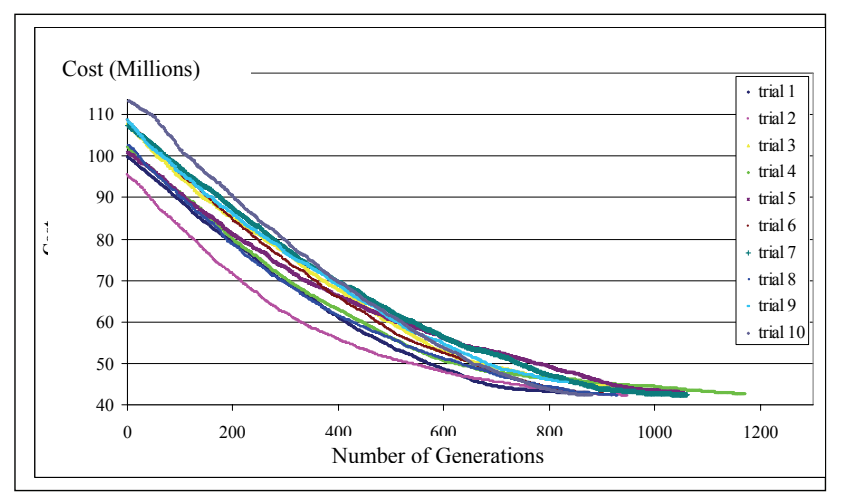

Fig. 6. Optimization patterns in different trials. A number of different trials were conducted (with different random seeds) to ascertain the robustness of the GA optimization.

\section{Model application: case study of Porto Alegre, Brazil}

The model has been applied to a part of the storm water drainage network of Porto Alegre, the capital city of the Brazilian state of Rio Grande do Sul. The case study area is the Arroio da Areia Basin. The basin occupies an area of $20.85 \mathrm{~km}^{2}$, of which approximately half $\left(11.7 \mathrm{~km}^{2}\right)$ corresponds to the Areia basin, and the remaining belongs to the Airport Polder. This study deals with the upstream part of the Areia basin.

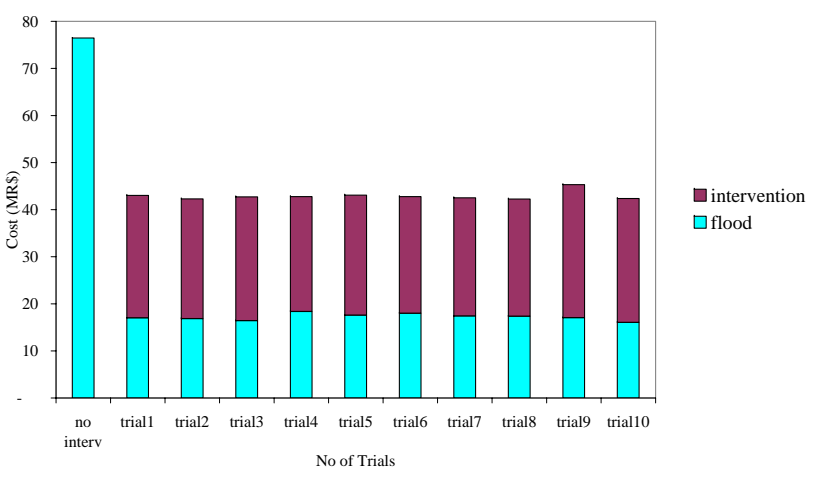

Fig. 7. Optimal costs scenarios in different trials.

\subsection{Modelled system description (sub catchment A)}

Sub catchment A is the upstream part of the Areia basin and occupies a drainage area of 236.8 hectare and can be sub divided into five zones (A1 to A5). The study area is drained through $2.412 \mathrm{~km}$ length of drainage networks at macro level.

The actual system consists of a simple drainage network with 12 nodes, 11 links and 17 sub catchments. Figure 5 shows the system network with the four most flooded nodes when analyzed for a $1 \mathrm{~h} 50$ years design storm.

\subsection{Optimal solutions}

The staged cost optimisation model is implemented for the Areia basin, and ten trials are run, using a flood unit cost of $100 \mathrm{R} \$ / \mathrm{m}^{3}$ and a discount rate of $2 \%$. The model output consists of the total optimized cost, maximum cost from which GA starts optimization, flood cost and intervention cost. The output results for the trials are studied in terms of the maximum values, minimum values, averages and standard deviations.

Figure 6 shows the convergence of the cost to minimum values for the ten trials. Figure 7 compares the best optimal solutions at different trials with the do nothing case. The best optimal value among the trials is equal to $\mathrm{R} \$ 42260000$. The number of generations in this trial is 927 and the cost is optimized by R $\$ 34200000$ (45\%) with respect to the do nothing scenario. The composition of the optimized cost consists of a flood cost of $\mathrm{R} \$ 17300000$ (41\%) and an intervention cost of R\$ 24900000 (59\%).

\subsubsection{Detention volumes at different trials in optimal solutions}

The corresponding detention volumes recommended for the optimal solutions in different trials vary, exploring the possibilities of different alternatives. Figure 8 shows the variation of the detention volumes at storage S1 at different trials and in different time steps. 


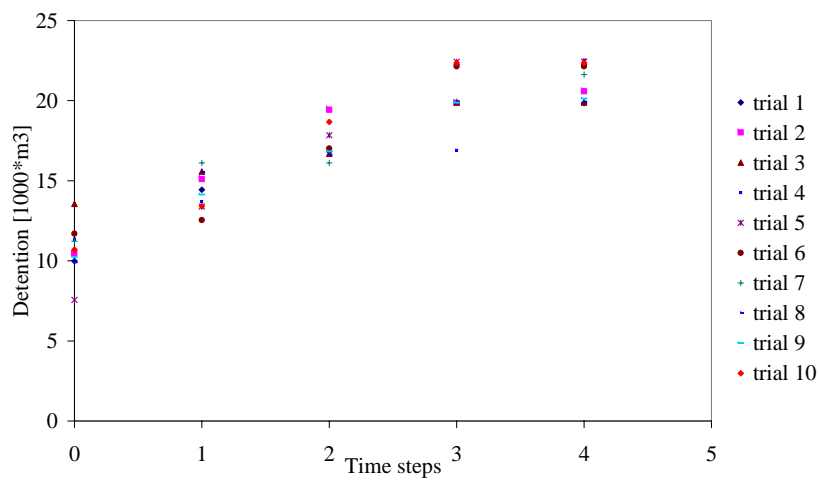

Fig. 8. Detention volumes at different trials for cost unit of $100 \mathrm{R} \$ / \mathrm{m}^{3}$ case.

Table 1. Recommended detention units for construction at different time and storages.

\begin{tabular}{cccccc}
\hline Storage & \multicolumn{5}{c}{ Time steps } \\
\hline & 0 & 1 & 2 & 3 & 4 \\
S1 & 10 & 16 & 17 & 20 & 20 \\
S2 & 0 & 0 & 4 & 4 & 4 \\
S3 & 5 & 7 & 7 & 10 & 10 \\
S4 & 0 & 0 & 1 & 1 & 1 \\
\hline
\end{tabular}

The recommended detention schedule from the best optimal trial (trial 8) in 1000 cubic meter units is given in Table 1. For example, 10 detention units are to be constructed in current year, then extended to 16 units in next 10 years, 17 units after 20 years, and 20 units after 30 years, after which, there is no need for further construction in the case of storage $\mathrm{S} 1$.

\subsubsection{Sensitivity with respect to the input data parameters}

There are numerous inputs in the present model that are based on quite broad assumptions, as was discussed in Sect. 3. Besides the change drivers, climate change and population growth, other important sources of uncertainty are the flood cost and discount rate. It is therefore important to examine the model's sensitivity to variations of these parameters. A number of sensitivity analyses were done in order to assure that the qualitative nature of the trends is not affected by the assumptions. Four of these tests are described below and in Fig. 9 to 12, where the uppermost line shows the cost in the do nothing case, the other solid lines show the costs for the staged option and the dotted lines show the corresponding costs in the "implement once and operate" option in all the tests.

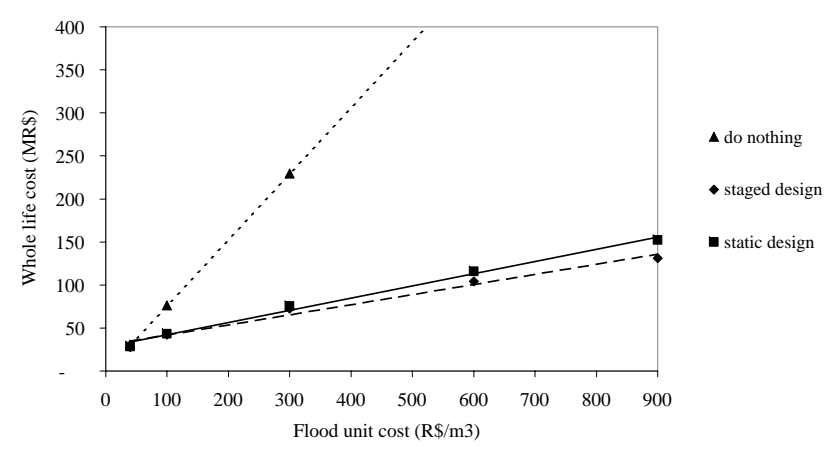

Fig. 9. Cost sensitivity with respect to the flood unit cost in staged and static options.

\section{Sensitivity to flood unit costs}

With a change in flood unit costs, the costs are increased with an increase in flood unit costs. The no intervention cost increases vary rapidly compared to other costs with intervention cases, as shown in Fig. 9. Thus, the effectiveness of provision of detention storage is higher when unit flood cost is higher.

\section{Sensitivity to rainfall increase rate}

With a change of rainfall increase rate, a linear change of optimized cost is observed, as shown in Fig. 10. It is observed that the total cost increases by $16 \%$ when the rainfall increase rate is increased by $100 \%$. It should be noted that decreases in rainfall increase rate have not been considered, but these are expected to follow the same linear trend.

\section{Sensitivity to population growth rate}

With change in population growth rate, the output data follow a linear trend. The total cost is increased by $32 \%$ when the population growth rate is increased by $100 \%$ (Fig. 11). Note that decreases in population growth rate have not been considered, but these are expected to follow the same linear trend.

\section{Sensitivity to discount rate}

The optimal costs follow a logarithmic trend with respect to discount rates. The smaller the discount rates, the higher the cost values. While the discount rate changed from $1 \%$ to $9 \%$, the no intervention cost reduced to $21 \%$ where as the total optimal cost reduced to 33\%, as shown in Fig. 12. The reduction for smaller costs is also smaller. 


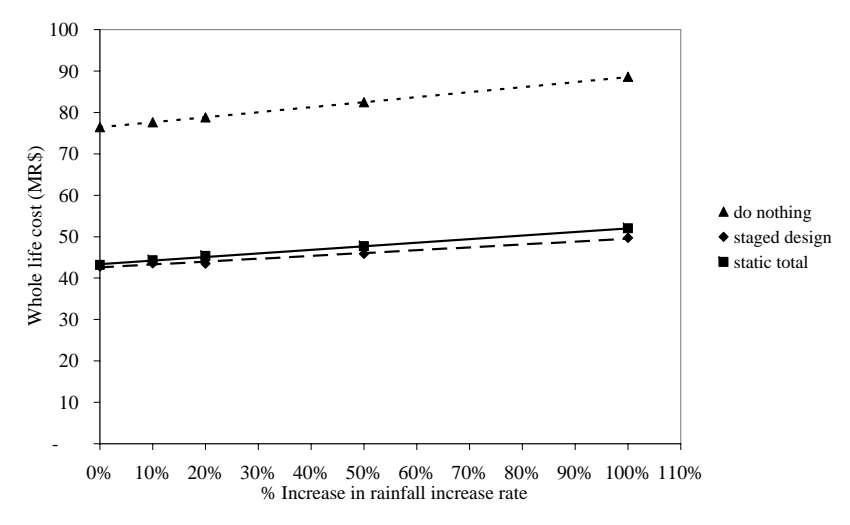

Fig. 10. Cost sensitivity with respect to rainfall increase rate in staged and static options.

\section{Discussion}

An automated cost-optimization tool to compute the costbenefit of staged intervention to reduce flood damage in urban drainage networks, based on hydraulic performance was implemented. The model takes into account the changes of the operating environment (both local and global) during the lifetime of the network in cost optimization analysis.

The tool was applied to a case study network representing a part of the city of Porto Alegre, Brazil. The application showed that the model can be used as a tool for decision making on staged construction plans, in order to reduce the total cost that comprises the investment cost and the damage due to residual floods, in terms of net present value. Under reasonable assumptions of population growth, rainfall change and inflation-adjusted discount rate, we showed that the option of staged intervention is significantly advantageous in financial terms.

As an example, the crude calculation made based on the stage damage relationship given by (Nascimento et al., 2006) urban floods are typically in the depths of about $0.2 \mathrm{~m}$ to $0.6 \mathrm{~m}$, the corresponding damage per cubic meter of flooded volume are approximately $201 \mathrm{R} \$$ to $170 \mathrm{R} \$ / \mathrm{m}^{3}$ and for the cost cases of 100 to 300 , the total cost savings found to be $1 \%$ to $4 \%$, consequently the flood cost is reduced by $7 \%$ to $25 \%$ more though the intervention costs are higher in staged option. For the optimized detention schedule shown in Table 1, thus, certain savings in total cost can be realized with reduced flood cost and at the same time more investments can be done as compared to the single stage implementation. This itself is a significant financial saving; however, this is only a part of the advantage of a staged construction policy. The staged approach inherently allows for flexibility in decision making that makes it possible for the decision maker to revise some decisions made today, in light of better information on a future date. For example the level of uncertainty on the rainfall during the last ten years of a project with 50 year

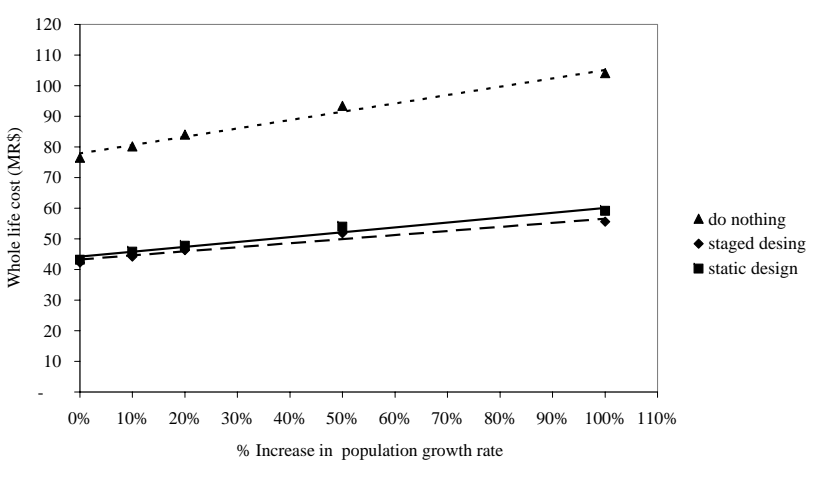

Fig. 11. Cost sensitivity with change in population growth rate (\%) in staged and static options.

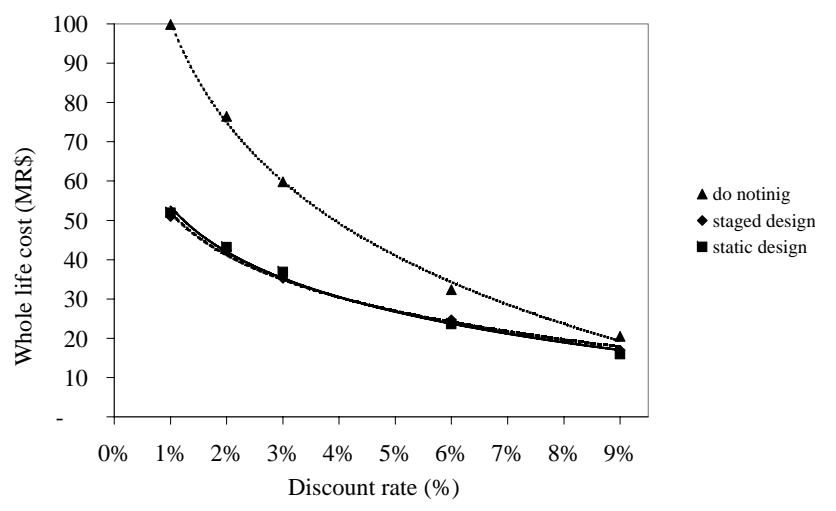

Fig. 12. Cost sensitivity with respect to discount rates in staged and static options.

life-span often will be much less at 25th year than it is at the inception of the project. Thus, even the proof that the staged approach is not costlier than a "implement once and operate" approach is adequate evidence in favor of the staged approach. However, at the same time, it should be borne in mind that such staged approaches are possible only for certain components of the whole urban drainage picture. For example staged increase of size of conveyance is often prohibitively expensive and thus makes little sense. However, other components, like detention storage, infiltration ponds, plot-scale interventions, etc., render themselves very well to this approach.

By provision of detention storages, in this case study, the flooding volume can be reduced by $85 \%$ due to 1 year storm, $80 \%$ due to 5 year storm, $72 \%$ due to 20 year storm and $49 \%$ due to 50 years storm. Thus, it helps better manage the flood volume using the existing drainage system (network) with provision of optional detention storages.

The contribution of the rainfall with smaller return periods is higher as compared to the higher return periods in terms of annual expected flood damage. However, in planning it is often necessary to consider issues beyond just financial cost. 
For example, large floods may cause less damage in terms of expected annual cost due to their low frequency, but when occurred they can be catastrophic, causing loss of human life. However, such floods are often related to rivers and are not caused by small urban watersheds.

Though the model works to search the optimal solution in a random probabilistic basis, the chance of finding local optimized value still exists (this is an inherent problem with genetic algorithms).

The model provides a contingency plan of detention storages based on the optimized cost values to be implemented for the network, which specifies the volume of detention storage to be provided and the intervention timing. This helps in decision making for the allocation of the resources as well as provides an implementation plan for flood management in the specified time frame. Also, the detention plan is well suited to a changing environment, as the possible impacts of urbanization as well as climate change have already been considered. Still, the reliability depends on the estimation of the changes in the environment.

The model is developed considering flood cost as penalty cost from nodal floods and the intervention costs only include the construction cost of the detention storages. Apart from these, other costs like maintenance cost of detention storages, repair and maintenance of network costs, planning and designing costs, initial construction costs etc. also affect the whole life cost. Thus it is better if all those costs can be incorporated in assessing the whole life cost.

\subsection{Uncertainties}

When detailed data is available, it is useful and interesting to analyze the urban systems in finer detail. However, in the present case study the available resolution of data limits the meaningful spatial detail of the hydraulic/hydrologic model. The main sources of data were the urban drainage master plan of Porto Alegre and experience of some site-visits. It is true that a large uncertainty is introduced as a result of the sparse data availability. However, many cities of the developing countries where rapid urbanization is a problem have similar data problems. In our opinion, a major source of uncertainty in this study arise from the assumptions made on flood costs. In the presence of this uncertainty, it is questionable whether it is useful to consider better spatial precision in the model.

\subsection{Major simplifications}

There are major simplifications in the fundamental steps of the procedure presented in this paper. Many of these are inevitable in the light of (1) the level of knowledge gaps that exist in the process of reasoning that is necessary in linking causes of change to their ultimate future impact in hydrologic cycle. These include (a) uncertainties in rainfall, demographic, landuse modeling, (b) linking average increase of rainfall to the changes in extreme values, etc., (2) in order to keep the focus on the "proof of concept" in applying WLC approach for sewer networks.

\section{Conclusions}

The major contribution of the present approach is to encourage a different philosophical direction in urban drainage planning and design, namely, to depart from a static, inception-stage implementation to a staged approach in urban flood defense. This is particularly useful in today's environment of highly dynamic changes in local and external forcings that make the design process quite uncertain. The staged approach provides the added advantage of flexibility to allow for change during the life time of a project. This approach can also help in resource limited situations that third world countries often face. It is usually more practical both in terms of financing and capacity to adopt a staged approach. We have shown that such an approach is possible as well as profitable in absolute financial terms.

Edited by: E. Toth

\section{References}

Bemfica, D. C.: Análise da aplicabilidade de padrões de chuva de projeto a Porto Alegre, Porto Alegre Universidade Federal do Rio Grande do Sul (UFRGS), Curso de Pós-Graduação em Recursos Hídricos e Saneamento Ambiental, 1999.

Campana, N. A. and Tucci, C.: Estimativa de área impermeável de macrobacias urbanas. Revista Brasileria de Engenharia, 12(N2), 79-94, 1994

Chow, V. T., Maidment, D., and Mays, L. W.: Applied Hydrology, McGraw-Hill, New York, 466-467, 1988.

Dutta, D., Herath, S., and Musiake, K.: A mathematical model for flood loss estimation, J. Hydrol., 277(1-2), 24-49, 2003.

EPA, US: Storm Water Management Model (SWMM), online: http: //www.epa.gov/ednnrmrl/models/swmm/index.htm (access date: December 2007), 2008.

Fraser, A. S.: Simulation of Genetic Systems by Automatic Digital Computers. I. Introduction, Aust. J. Biol. Sci., 10, 484-491, 1957.

Goldberg, D. E.: Genetic Algorithms in Search, Optimization and Machine Learning, Kluwer Academic Publishers, Boston, MA, USA, 372 pp., 1989.

Gruntfest, E. and Ripps, A.: Flash floods - warning and mitigation efforts and prospects, edited by: Parker, D., Routledge, 377-390, 2000.

Gupta, R. S.: Hydrology and Hydraulic Systems, Waveland Press Inc., Long Grove, IL, 2nd ed., 2001.

Houghton, J. T., Ding, Y., Griggs, D. J., Noguer, M., van der Linden, P. J., Dai, X., Maskell, K., and Johnson, C. A.: Climate change 2001: The scientific basis, Cambridge University Press, Cambridge, 881 pp., 2001.

Mitchell, T.: Machine Learning, McGraw Hill, 423 pp., 1997. 
Nascimento, N., Baptista, M., Silva, A., Léa Machado, M., Costa de Lima, J., Gonalves, M., Silva, A., Dias, R., and Machado, É.: Flood-damage curves: Methodological development for the Brazilian context in Water Practice \& Technology, 1, 1, 2006.

Rossman, L. A.: Storm Water Management Model User's Mannual, US Environmental Protection Agency, Cincinnati, 2004.

Sapir, D. G.: Disaster Data: A Balanced Perspective: Natural disasters in 2007, CRED CRUNCH, Brussels, Belgium, 2008.
Shepherd, W., Cashman, A., Djordjevic, S., Dorini, G, Saul, A., Savic, D., Lewis, L., Walters, G., and Ashley, R.: Whole life costing of sewer systems, in: Proceedings of WaPUG Autumn Meeting, http://www.ciwem.org/groups/wapug/A2004 shepherd.pdf, Blackpool, England, 10-12 November 2004.

Woods-Ballard, B., Kellagher, R., Martin, P., Jefferies, C., Bray, R., and Shaffer, P.: Sustainable Urban drainage systems, design mannual, CIRIA, CIRIA Classic House 174-180 Old Street London EC1V 9BP UK, C697, 2007. 